NASA/TM-2000-209791

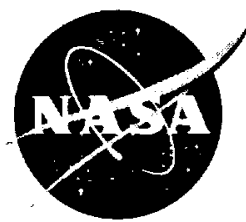

\title{
Technology Development for a Stirling Radioisotope Power System
}

Lanny G. Thieme

Glenn Research Center, Cleveland, Ohio

Songgang Qiu and Maurice A. White

Stirling Technology Company, Kennewick, Washington 
Since its founding, NASA has been dedicated to the advancement of aeronautics and space science. The NASA Scientific and Technical Information (STI) Program Office plays a key part in helping NASA maintain this important role.

The NASA STI Program Office is operated by Langley Research Center, the Lead Center for NASA's scientific and technical information. The NASA STI Program Office provides access to the NASA STI Database, the largest collection of aeronautical and space science STI in the world. The Program Office is also NASA's institutional mechanism for disseminating the results of its research and development activities. These results are published by NASA in the NASA STI Report Series, which includes the following report types:

- TECHNICAL PUBLICATION. Reports of completed research or a major significant phase of research that present the results of NASA programs and include extensive data or theoretical analysis. Includes compilations of significant scientific and technical data and information deemed to be of continuing reference value. NASA's counterpart of peerreviewed formal professional papers but has less stringent limitations on manuscript length and extent of graphic presentations.

- TECHNICAL MEMORANDUM. Scientific and technical findings that are preliminary or of specialized interest, e.g., quick release reports, working papers, and bibliographies that contain minimal annotation. Does not contain extensive analysis.

- CONTRACTOR REPORT. Scientific and technical findings by NASA-sponsored contractors and grantees.
- CONFERENCE PUBLICATION. Collected papers from scientific and technical conferences, symposia, seminars, or other meetings sponsored or cosponsored by NASA.

- SPECIAL PUBLICATION. Scientific, technical, or historical information from NASA programs, projects, and missions, often concerned with subjects having substantial public interest.

- TECHNICAL TRANSLATION. Englishlanguage translations of foreign scientific and technical material pertinent to NASA's mission.

Specialized services that complement the STI Program Office's diverse offerings include creating custom thesauri, building customized data bases, organizing and publishing research results ... even providing videos.

For more information about the NASA STI Program Office, see the following:

- Access the NASA STI Program Home Page at http://wwww.sti.nasa.gov

- E-mail your question via the Internet to help@sti.nasa.gov

- Fax your question to the NASA Access Help Desk at (301) 621-0134

- Telephone the NASA Access Help Desk at (301) 621-0390

- Write to: NASA Access Help Desk NASA Center for AeroSpace Information 7121 Standard Drive Hanover, MD 21076 
NASA/TM-2000-209791

\section{Technology Development for a Stirling Radioisotope Power System}

Lanny G. Thieme

Glenn Research Center, Cleveland, Ohio

Songgang Qiu and Maurice A. White

Stirling Technology Company, Kennewick, Washington

Prepared for the

2000 Space Technology and Applications International Forum

sponsored by the American Institute of Physics

Albuquerque, New Mexico, January 30-February 3, 2000

National Aeronautics and

Space Administration

Glenn Research Center 
Trade names or manufacturers' names are used in this report for identification only. This usage does not constitute an official endorsement, either expressed or implied, by the National Aeronautics and Space Administration.

Available from

NASA Center for Aerospace Information

National Technical Information Service 5285 Port Royal Road 7121 Standard Drive Springfield, VA 22100

Hanover, MD 21076 Price Code: A03 


\title{
TECHNOLOGY DEVELOPMENT FOR A STIRLING RADIOISOTOPE POWER SYSTEM
}

\author{
Lanny G. Thieme \\ National Aeronautics and Space Administration \\ Glenn Research Center \\ Cleveland, Ohio 44135 \\ Songgang Qiu and Maurice A. White \\ Stirling Technology Company \\ Kennewick, Washington 99336
}

\begin{abstract}
NASA Glenn Research Center and the Department of Energy are developing a Stirling convertor for an advanced radioisotope power system to provide spacecraft on-board electric power for NASA deep space missions. NASA Glenn is addressing key technology issues through the use of two NASA Phase II SBIRs with Stirling Technology Company (STC) of Kennewick, WA. Under the first SBIR, STC demonstrated a synchronous connection of two thermodynamically independent free-piston Stirling convertors and a 40 to 50 fold reduction in vibrations compared to an unbalanced convertor. The second SBIR is for the development of an Adaptive Vibration Reduction System (AVRS) that will essentially eliminate vibrations over the mission lifetime, even in the unlikely event of a failed convertor. This paper presents the status and results for these two SBIR projects and also discusses a new NASA Glenn in-house project to provide supporting technology for the overall Stirling radioisotope power system development. Tasks for this new effort include convertor performance verification, controls development, heater head structural life assessment, magnet characterization and thermal aging tests, FEA analysis for a lightweight alternator concept, and demonstration of convertor operation under launch and orbit transfer load conditions.
\end{abstract}

\section{INTRODUCTION}

NASA Glenn Research Center and the Department of Energy (DOE) are developing a Stirling convertor for an advanced radioisotope power system to provide spacecraft on-board electric power for NASA deep space missions. Stirling is being evaluated as an alternative to replace Radioisotope Thermoelectric Generators (RTGs) with a highefficiency power source. The efficiency of the Stirling system, about 25 percent for this application, will reduce the necessary isotope inventory by a factor of 3 or more compared to RTGs. Stirling is the most developed convertor option of the advanced power concepts under consideration (Frazier, 1998 and Mondt, 1998).

DOE is developing the radioisotope Stirling convertor under contract with Stirling Technology Company (STC) of Kennewick, WA (White, 1998 and 1999). Two 55-We convertors are now being tested by STC in a dynamicallybalanced opposed arrangement, as shown in figure 1. Both design convertor power and efficiency have been demonstrated. NASA Glenn is providing technical consulting for this effort under an Interagency Agreement with DOE.

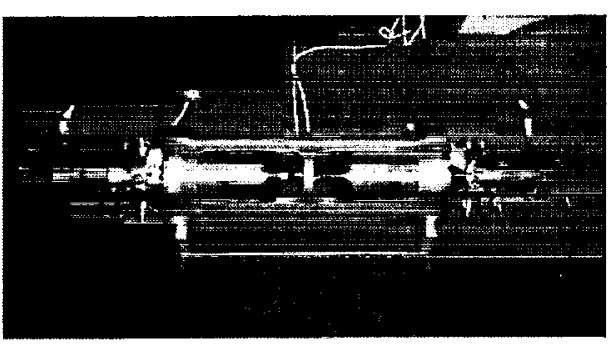

FIGURE 1. Two opposed 55-We convertors on test.
The design of the 55-We Stirling convertor is based on previous successful STC development efforts, particularly those for the 10 -We radioisotope terrestrial convertor, $\mathrm{RG}-10$, and the $350-\mathrm{We}$ RG-350 aimed at commercial cogeneration and remote power (Erbeznik, 1996). One RG-10 has now been on life test for over 50,000 hours (5.7 years) with no convertor maintenance and no degradation in performance. Another RG-10 convertor has recently been fueled with isotope and field testing is beginning. Multiple units of the RG-350 and their companion BeCOOL cryocoolers have accumulated over 80,000 total hours of operation, much of this at independent third-party test sites. STC has also completed extensive component life testing and, in particular, has over 1000 years of total test time (230 flexures) on the critical flexural bearings. These numerous test hours on various systems and on key components provide a high confidence that the 55 -We convertor will meet its life and reliability goals. 
NASA Glenn has been investigating Stirling radioisotope power systems for deep space missions since about 1990. This work grew out of earlier Stirling efforts conducted for DOE for a Stirling automotive engine and for the NASA Civil Space Technology Initiative (CSTI) to develop Stirling for a nuclear power system to provide electrical power for a lunar or Mars base (part of the SP-100 program). NASA Glenn also provided technical management for DOE for the Advanced Stirling Conversion System (ASCS) terrestrial dish Stirling project. Overall, NASA Glenn has been developing Stirling technologies since the mid-1970's.

As part of the overall Stirling radioisotope convertor development, NASA Glenn is addressing key technology issues through the use of two NASA Phase II Small Business Innovation Research (SBIR) contracts with STC. NASA Glenn has also just started an in-house project to provide additional supporting technology developments. This paper will discuss the status and results from these SBIR contracts and describe the tasks to be accomplished as part of the new NASA Glenn efforts.

Systems using Stirling convertors are being analyzed by NASA Glenn for other space applications in addition to Stirling radioisotope power for deep space missions. These include solar dynamic power systems for space-based radar (Mason, 1999) and as a deep space alternative to the radioisotope system, a combined electrical power and cooling system for a Venus lander, and lunar/Mars bases and rovers.

\section{SYNCHRONOUS OPERATION OF OPPOSED STIRLING CONVERTORS}

STC, as part of a NASA Phase II SBIR contract, has successfully demonstrated synchronous operation of two thermodynamically independent free-piston Stirling convertors with linear alternators connected electrically in parallel. Previous Stirling development had focused on single convertors and had not addressed how to connect multiple convertors in a system. However, in most potential space applications, multiple convertors are important for redundancy and modularity. Thermodynamically independent convertors allow one convertor to fail without affecting the performance of the other. Finally, the use of multiple convertors is important to controlling vibrations, a critical issue for a dynamic space power system. Synchronization of convertor pairs operating in an opposed configuration provides balanced operation with minimal vibration.

Two RG-350 convertors were used for this development. Initial efforts included computer simulations of multipleconvertor connection methods and single-convertor baseline testing of each of the RG-350 convertors. Each convertor was tested separately over a range of hot-end and cold-end temperatures and charge pressures. Approximately $5 \mathrm{~g}$ 's vibration was measured at the nominal conditions for a single convertor.

During multiple-convertor testing, synchronization was achieved with the two convertors (see figure 2) operating over a wide range of conditions. The frequency of each convertor was identical, and the pistons operated nominally 180 degrees out-of-phase mechanically. The convertors were connected electrically in parallel and mechanically through external attachments on the cold-end pressure vessels. A mechanical coupler was developed that aligns the two convertors and can compensate for any inherent misalignments. Synchronization produced a 40 to 50 fold reduction in vibrations compared to an unbalanced convertor, a value that appears to be well below pixel smear limits for deep space sensing. Equal power generation between the two convertors was demonstrated under nominal conditions. This connection method is now being used to connect the DOE/STC 55-We convertors.

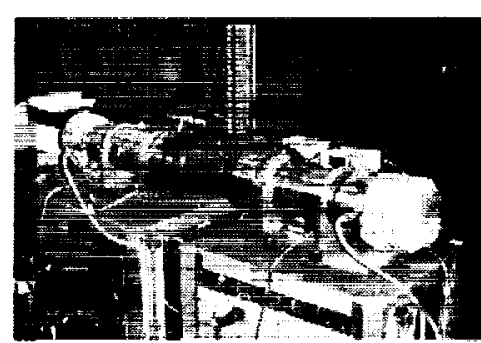

FIGURE 2. Stirling convertors synchronized for system operation with low vibrations.
The synchronization was shown to be very robust by testing at conditions of simulated degradation and by transient testing. For one set of runs, the average hot-end temperature of one convertor was varied widely while holding the other convertor hot-end temperature nearly constant at about $600^{\circ} \mathrm{C}$. Synchronization was maintained over this range, and figure 3 shows the effects on the phase difference between the power pistons and the maximum vibration measured on the two convertors. Zero-degree phase lag indicates the pistons are operating 180 degrees out-of-phase mechanically. The maximum vibration increased from $0.12 \mathrm{~g}$ to just $0.48 \mathrm{~g}$ over this wide range of operation; this is compared to about $5 \mathrm{~g}$ 's vibration for an unbalanced convertor. The convertor power output at the lowest temperature was about 20 percent of the power output for the convertor operating at about $600^{\circ} \mathrm{C}$. 


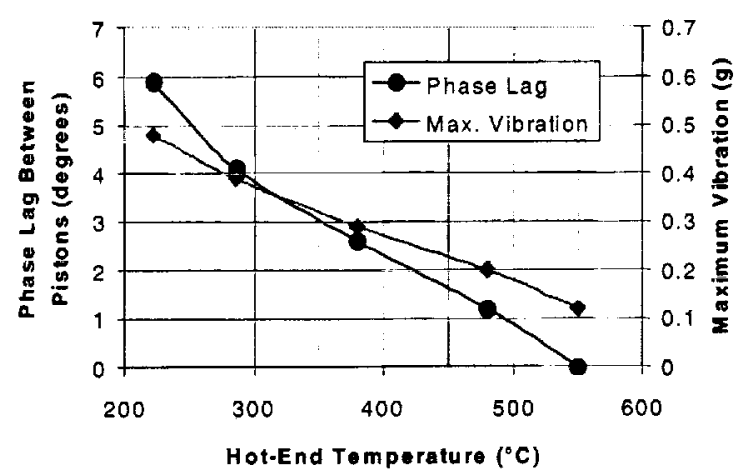

FIGURE 3. Response of the maximum vibration and phase lag between pistons when the hot-end temperature of one convertor of a fully coupled pair is varied.

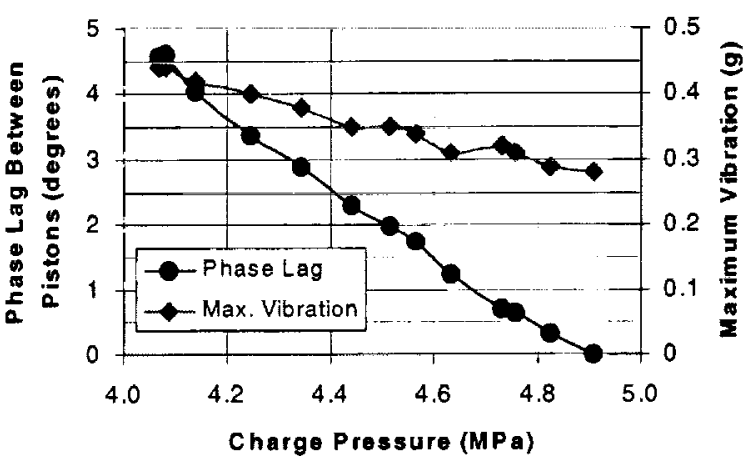

FIGURE 4. Response of the maximum vibration and phase lag between pistons when the charge pressure of one convertor of a fully coupled pair is varied.

Charge pressure variations of up to 20 percent for one convertor while maintaining constant charge pressure in the other and constant power input to each were also tested. Results for this case are shown in figure 4 . Again, synchronization was maintained, and only small increases in vibration were measured. These tests were run with an earlier version of the mechanical coupler so the vibration level at the nominal design condition is somewhat higher than that shown in figure 3. Power output remained essentially the same for each convertor over this range; this was as expected from the single-convertor test results.

Transient data taken during various electrical connections and disconnections of the two convertors showed the ability to achieve synchronization reliably and rapidly. No significant transient overstrokes were seen or any other potentially damaging results. Figure 5 shows transient traces for the piston and displacer motions,

Voltage

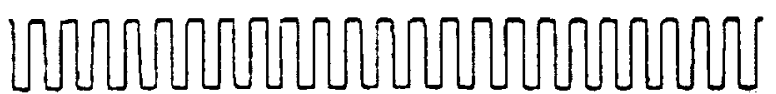

Current WWMMWWMMMM

Piston and Displacer Positions

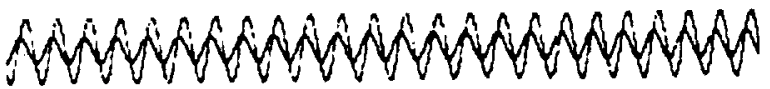

Vibrations

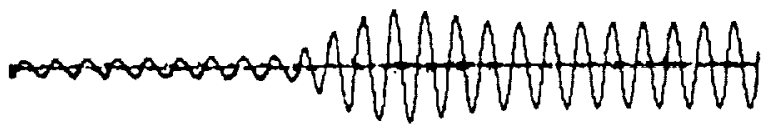

FIGURE 5. Transient response when the parallel electrical connection is broken and one convertor is shut down. automotive batteries were connected in series and tests run over a range of convertor hot-end temperatures and battery state-of-charge. Operation was found to be essentially the same as when dissipating power to the controller internal load resistors.

Tests were also run with the electrical coupling only and with the mechanical coupling only. With only the electrical coupling, the convertors synchronized as before; however, there was no reduction in vibrations as there was no mechanical connection between the convertors. With only the mechanical coupling, there was at most a weak synchronous connection, and the vibrations were similar to a single unbalanced convertor. 
A further innovation during this SBIR project was the demonstration of an artificial neural network (ANN) that could potentially be used to monitor the health of a convertor using only non-invasive instrumentation that does not penetrate the convertor pressure vessel. The ANN successfully predicted piston and displacer amplitudes and phasing for a 10-We RG-10 convertor using voltage, current, and rejection temperature as the only inputs. Simulated pressure degradation for one of the fully coupled RG-350 convertors was also successfully tracked using current, current-voltage phasing, and output power for each convertor as inputs. It is felt that the ANN has a high probability of detecting any convertor degradation that may occur without needing any internal instrumentation that would decrease the convertor reliability. This could then allow the system controller to adjust operation to maximize system performance.

\section{ADAPTIVE VIBRATION REDUCTION SYSTEM}

Under a second NASA Phase II SBIR, STC is developing an Adaptive Vibration Reduction System (AVRS) that will further reduce vibration levels by a factor of 10 or more under normal operating conditions. It will achieve this with an active balance system with feedback from a vibration signal and will cancel the fundamental vibration and up to 10 harmonics. Even more importantly, the AVRS will be adaptive and will add the ability to adjust to any changing convertor conditions over the course of a mission. Thus, it should allow successful dynamic balancing over the mission lifetime and will be able to demonstrate its adaptive ability through up-front testing. The AVRS is now being developed on two RG-350 convertors and will also be demonstrated on the DOE/STC 55-We convertors.

The AVRS will use a balance mass driven by a separate linear motor; only one balance mass and motor are needed for two opposed Stirling convertors. A balance mass and motor being used in the first AVRS testing with the RG350 convertors is shown in figure 6 . The vibration signal will be measured with either a load cell or an accelerometer. A fast Fourier transform of this signal will then be used to construct a compensation signal that will be sent to the balance motor through a power amplifier. Both the amplitude and phase of each harmonic will be adjusted. The motion of the balance mass center-of-gravity will be opposed to and proportional to the motion of the center-of-gravity of the combined system of two pistons and two displacers. The AVRS will adjust to any change in convertor operating conditions, any convertor degradation that may occur over a mission, or even in the unlikely event of a convertor failure.

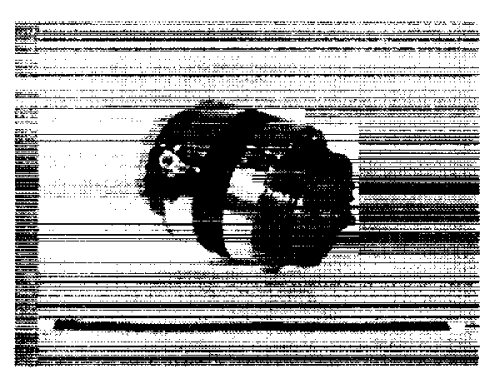

FIGURE 6. AVRS balance mass and motor for RG-350 testing.
Stirling cryocoolers are currently used to cool vibration-sensitive sensors in space applications. STC has demonstrated a cryocooler vibration level of only $0.007 \mathrm{~g}$ 's using similar technology to the AVRS. This technique has been shown to be effective with reasonable power and mass budgets. One key difference for balancing power convertors is that the frequency is not fixed as it is in coolers. Thus, the frequency must be measured on a continual basis and factored into the control algorithm.

Initial tests of the AVRS on the RG-350 have shown a 500 fold reduction in unbalanced vibrations under normal operating conditions with two synchronized convertors in an opposed configuration. This compares to the 40 to 50 fold reduction with just the synchronized convertors and was accomplished with only $2 \mathrm{~W}$ of power dissipation. Testing was also done with a simulated failed convertor, and a 50 -fold vibration reduction was obtained with only $7 \mathrm{~W}$ of power dissipation; this power dissipation scales to less than 2 to $3 \mathrm{~W}$ for a $55-\mathrm{We}$ convertor. These initial tests only balanced the fundamental of the vibration signal (no harmonics) and, thus, vibration levels should be even further decreased as development of the full control algorithm is completed.

A further task of this contract will demonstrate a passive heat rejection system for both the RG-350 and the $55-\mathrm{We}$ convertors. Initial system studies completed by Orbital Sciences Corporation (Schock, 1999) used a heat pipe to transport the convertor waste heat to the radiator. Design and fabrication are currently being completed for an aluminum hub clamped to the Stirling rejector with multiple water heat pipes inserted into the hub to demonstrate this cooling concept on the RG-350. Thermacore, Inc. is consulting on this effort and providing the heat pipes. 


\section{NASA GLENN SUPPORTING TECHNOLOGY DEVELOPMENT FOR THE STIRLING RADIOISOTOPE CONVERTOR}

NASA Glenn has recently initiated an in-house technology development project in support of developing the Stirling radioisotope power system for deep space missions. The project tasks build on NASA Glenn expertise developed as part of previous Stirling research, especially for the Stirling space power development during the NASA CSTI project (Niedra, 1994; Abdul-Aziz, 1995; and Rauch, 1995). Tasks were identified in the appropriate areas where value-added development is provided as part of the overall Stirling radioisotope effort. Each task is described below.

Two RG-350 convertors (see figure 2) and two 55-We convertors (see figure 1) will be tested in synchronous opposed configurations. This will provide an independent performance verification for the 55-We convertors to be used for the radioisotope application. The primary emphasis will be on technology development for a reliable, lightweight integrated control system for multiple convertors and multiple system loads. Heat transfer characteristics of high porosity regenerators will also be determined using an existing heat transfer test rig.

Heater head life is a critical element for achieving the $100,000+$ hour life of the convertor. NASA Glenn materials and structures personnel will perform an independent thermal and structural analysis; characterize creep properties for the Inconel 718 heater head material in the final condition that will be used in the convertor; adapt, verify, and characterize life prediction models; and then use these models to assess heater head life. Heater head tests to failure will also be conducted. Successful completion of these efforts should give high confidence in the ability of the heater head to meet the operational life requirements. A materials review and an evaluation of joining methods will also be included. A test rig conducting biaxial creep testing is shown in figure 7.

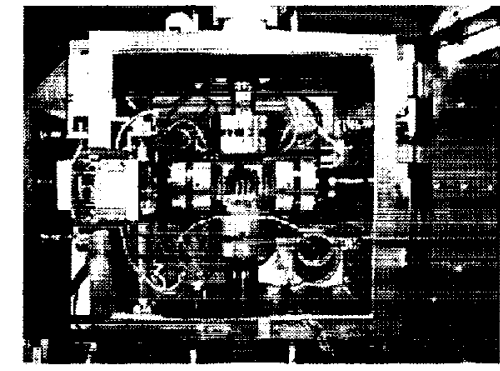

FIGURE 7. Biaxial creep testing.

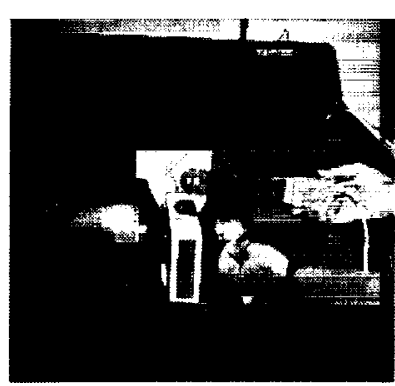

FIGURE 8. Magnet characterization test rig.

FeNdB permanent magnets are currently being used in the 55-We convertors. Specific magnet choice is dependent on the final convertor cold-end temperature chosen based on system analyses (now expected to be between 80 and $120^{\circ} \mathrm{C}$ ), magnet temperature calculations, and the safety margin necessary to prevent demagnetization. Characterization testing of appropriate $\mathrm{FeNdB}$ magnets will first be done using an existing test rig that was developed for testing SmCo magnets during the previous NASA CSTI research for SP-100 (see figure 8). Selected FeNdB and possibly SmCo magnets will then be put on aging tests at various temperature levels and in a demagnetizing field to quantify any potential magnet degradation with time and temperature. Such degradation could affect both the remanent magnetization and the demagnetization resistance. This task will also include a finite element analysis (FEA) of a lightweight linear alternator concept that has been previously tested by STC and had performance shortfalls. The FEA will be used to evaluate the alternator flux profiles and potential design modifications to improve performance.

The two 55-We convertors will be tested in the vibration test facility of the NASA Glenn Structural Dynamics Laboratory, shown in figure 9, to demonstrate their ability to operate under launch and orbit transfer load conditions. The Structural Dynamics Laboratory will provide analysis, mounting structure, and testing for this effort. The convertor load-carrying capability for these loads is provided by an aft bearing that has been added to the design for this purpose. NASA Glenn tribology personnel will provide consulting relative to understanding the characteristics of this bearing.

As part of the Interagency Agreement with DOE, NASA Glenn conducted an extensive conceptual screening of heat pipe and non-heat pipe (figure 10) radiator concepts for both two- and four-convertor radioisotope Stirling power systems. The starting point for the studies was based on the Orbital Sciences Corporation system layout using heat pipe radiators (Schock, 1999). Various material options were analyzed including standard state-of-the-art materials and more advanced high thermal conductivity materials. A further task in this new NASA in-house effort is expected to continue this radiator evaluation and include both view factor and FEA analyses. 


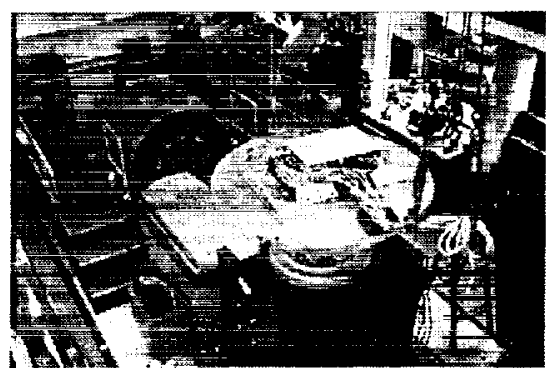

FIGURE 9. Vibration Test Facility at NASA Glenn.

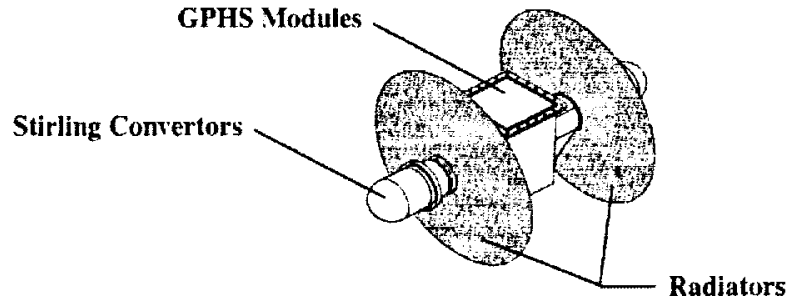

FIGURE 10. Non-heat pipe radiator concept.

\section{CONCLUDING REMARKS}

NASA Glenn Research Center and the Department of Energy are developing a Stirling convertor for an advanced radioisotope power system to provide spacecraft on-board electric power for NASA deep space missions. Stirling is being evaluated as an alternative to replace RTGs with a high-efficiency power source. STC, under contract to DOE, is making rapid progress in developing and demonstrating the 55-We convertor. Under two NASA Phase II SBIRs, STC has developed a synchronous system connection for multiple convertors and demonstrated very low vibration levels based on this synchronous connection and an adaptive vibration reduction system. NASA Glenn is now starting an in-house supporting technology development to provide further key inputs, including a heater head life assessment, permanent magnet aging characteristics, and demonstration of convertor operation under launch and orbit transfer loads.

\section{REFERENCES}

Abdul-Aziz, A., Bartolotta, P., Tong, M., and Allen, G., “An Experimental and Analytical Investigation of Stirling Space Power Convertor Heater Head," NASA TM-107013, 1995.

Erbeznik, R.M. and White, M.A., "Test Results and Commercialization Plans for Long Life Stirling Generators," Proceedings of the $31^{\text {st }}$ Intersociety Energy Conversion Engineering Conference, edited by P.R.K. Chetty et al., Institute of Electrical and Electronics Engineers, 1996, Vol. 2, pp. 1265-1270.

Frazier, T.A., "Advanced Conversion Technology Review Panel Report," in Meeting Global Energy and Environmental Needs, Proceedings of the $33^{\text {rd }}$ Intersociety Energy Conversion Engineering Conference, American Nuclear Society, 1998, Paper IECEC-98-398.

Mason, L.S., "Technology Projections for Solar Dynamic Power," NASA/TM-1999-208851, 1999.

Mondt, J.F. and Nesmith, B.J., "Advanced Convertor Technology Evaluation and Selection for ARPS," in Space Technology and Applications International Fortun, edited by M.S. El-Genk, AIP Conference Proceedings 420, American Institute of Physics, 1998, Part Three, pp. 1098-1105.

Niedra, J.M., "Comparative M-H Characteristics of 1-5 and 2-17 Type Samarium-Cobalt Permanent Magnets to 300 C," NASA CR-194440, 1994.

Rauch, J.S. and Kankam, M.D., "Transient and Steady-State Tests of the Space Power Research Engine with Resistive and Motor Loads," NASA TM-106832, 1995.

Schock, Alfred, Or, Chuen, and Kumar, Vasanth, "Radioisotope Power System Based on Improved Derivative of Existing Stirling Engine and Alternator," in Space Technology and Applications Intemational Fontu 1999, edited by M.S. El-Genk, AIP Conference Proceedings 458, American Institute of Physics, 1999.

White, M.A., Qiu, S., Erbeznik, R.M., Olan, R.W., and Welty, S.C., "Status of an Advanced Radioisotope Space Power System Using Free-Piston Stirling Technology," in Meeting Global Energy and Environmental Needs, Proceedings of the $33^{\text {rd }}$ Intersociety Energy Conversion Engineering Conference, American Nuclear Society, 1998, Paper IECEC-98-417.

White, M.A., Qiu, S., Olan, R.W., and Erbeznik, R.M., "Technology Demonstration of a Free-Piston Stirling Advanced Radioisotope Space Power System," in Space Technology and Applications Intermational Forum 1999, edited by M.S. El-Genk, AIP Conference Proceedings 458, American Institute of Physics, 1999. 
.

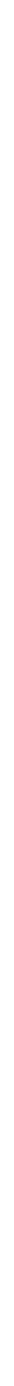




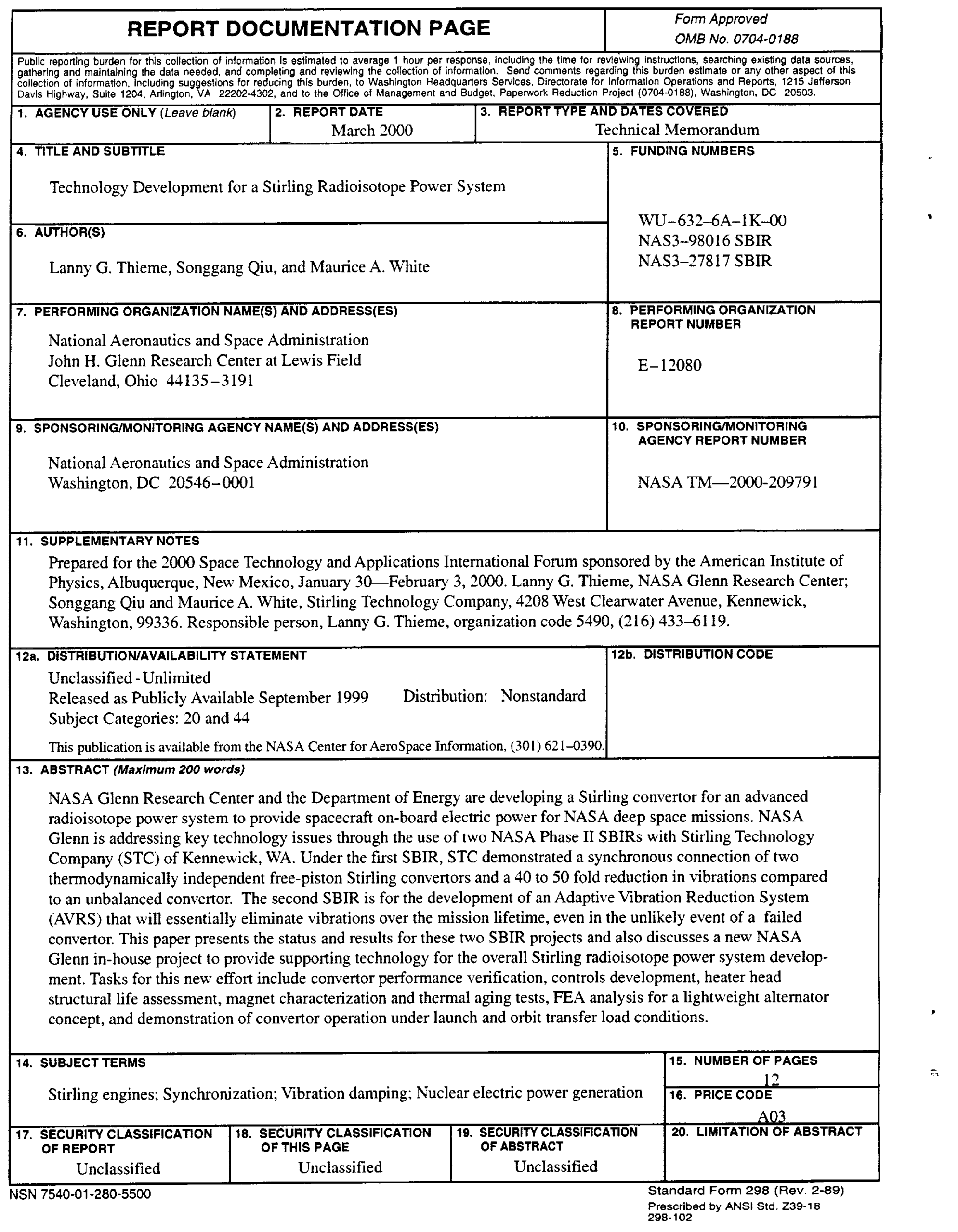

